November - 2009

\title{
Open Textbook Proof-of-Concept via Connexions
}

\author{
Judy Baker \\ Foothill College, USA
}

\author{
Joel Thierstein \\ Rice University and Connexions, USA
}

\section{Kathi Fletcher, Manpreet Kaur, and Jonathan Emmons \\ Connexions, USA}

\begin{abstract}
To address the high cost of textbooks, Rice University's Connexions and the Community College Open Textbook Project (CCOTP) collaborated to develop a proof-of-concept free and open textbook. The proof-of-concept served to document a workflow process that would support adoption of open textbooks. Open textbooks provide faculty and students with a low cost alternative to traditional publishers' textbooks and can help to make higher education more affordable. Connexions provides a publishing platform for open textbook projects. The CCOTP acted as a liaison between community college faculty, open textbook authors, and Connexions. Challenges to the production and adoption of open textbooks include 1) faculty members' and students' expectations of high production quality and ancillaries for open textbooks, 2) methods for documenting and maintaining control over various versions, and 3) the process of converting existing open content to digital and accessible formats. Connexions holds promise as a means to overcome these challenges.

Connexions identified lessons learned about open textbook production, such as the importance of a style guide, the advantage of assembly-line workflow, and the importance of naming conventions and standard math authoring tools. Connexions also identified lessons learned about open textbook use by students and faculty, e.g., the value of availability and customizability, the importance of interactivity, the difference in how faculty and students view modularity, and the importance of textbook reading navigational aids. The authors note that the CCOTP recommends using Connexions as the common repository for open textbook content in an effort to provide greater national and international access.
\end{abstract}

Keywords: Open textbook; Connexions; open educational resources; OER; repository; community college 


\section{Open Textbooks}

Community colleges educate $44 \%$ of the nation's undergraduates and $50 \%$ of the nation's teachers. For many of those students, affordability is critical. They may be the first generation in their family to attend college and often work while going to school. The high cost of textbooks presents a barrier to college for many of them. Solutions to this problem have been proposed and even legislated but no one solution will be adequate to fully address this complex issue. In the absence of meaningful solutions by colleges, some students are resorting to behaviors that undermine academic integrity (Young, 2008). Furthermore, some educators are frustrated by the tedious process of producing their own published textbooks as well as by copyright restrictions on content that is freely available via the Internet (Baker, 2005). They yearn for an easier way to customize learning content for their students (Buczynski, 2007). During 2008, the Community College Consortium for Open Educational Resources (CCCOER) collaborated with Rice University's Connexions to address the high cost and intractable nature of traditional textbooks with a proof-of-concept open textbook.

CCCOER was established by the Foothill-De Anza Community College District in July 2007 and its membership is now made up of 93 community colleges in the U.S. and one in Ontario, Canada. The primary goal of CCCOER is to identify, create, or repurpose existing open educational resources (OER) as open textbooks and to make them available for use by community college students and faculty. From 2007 through 2008, Foothill-De Anza Community College District conducted a nationwide survey of 1,203 faculty members (Baker, 2008). The study findings indicate a large gap between those willing to use open educational resources (OER) in their classes (91\%) and those actively using OER (34\%). The dual challenges of locating and inspiring the use of fully vetted, high-quality OER and open textbooks targeted for community college students and faculty contribute to this gap.

The Community College Open Textbook Project (CCOTP) was launched in March 2008 to address this gap between willingness and action. The CCOTP was funded by The William and Flora Hewlett Foundation as a one- year feasibility study in partnership with the Foothill-De Anza Community College District, the Monterey Institute for Technology and Education, Rice University's Connexions, University of California College Prep, Flat World Knowledge, California State University System's Digital Marketplace, the Institute for the Study of Knowledge Management in Education, the High Tech Center Training Unit, and the Student Public Information Research Group. The aim of the CCOTP was to identify and study sustainable models for promoting the development and use of open textbooks at community colleges, to document sustainable workflow approaches for producing, maintaining, and disseminating open textbooks, and to centralize critical open textbook information for use by community college professors and other interested parties.

Raising the awareness and knowledge of faculty, administrators, and staff about open textbooks and open educational resources presented a major challenge for the CCOTP, especially when the use of expensive traditional textbooks is deeply ingrained as normative in institutional processes. Existing processes at many colleges and universities assume that instructors prefer to adopt 
publishers' traditional textbooks with the consequence that those who seek alternatives are not as well supported by the institution. By gaining administrators' buy-in to the CCCOER, institutional support for use of open textbooks is more likely. An outcome of the CCCOER and its CCOTP is increased awareness of viable alternatives to expensive traditional textbooks. And as the use of open textbooks becomes more normative and legitimized, colleges will find it easier to establish articulation agreements that honor transfer of courses that use open textbooks.

The CCOTP identified several challenges to the production and adoption of open textbooks: 1) faculty members' and students' expectations of high production quality and ancillaries for open textbooks, 2) methods for documenting and maintaining control over various versions, and 3) the process of converting existing open content to digital and accessible formats.

Often publishers' textbooks are inappropriate for use in community college courses because they contain far more information than is actually needed, or they contain generic information that lacks regional, local, or cultural relevance to diverse community college student populations. Faculty who have become familiar and comfortable with the idea of using open textbooks as a result of the CCOTP have the option of customizing the learning materials to best suit their own teaching style and any unique needs of their students. This means that students are only using the parts of a textbook that are relevant to their own studies.

Open textbooks are available in a variety of digital formats, which can lower educational costs for students without having a negative impact on learning (Annand, 2008). Additionally, open textbooks, by their very nature, can be vetted by the entire community of college faculty as well as by academics researching effective teaching materials. Making information available about open textbooks, however, requires new models. The CCOTP contributes to an efficient use of resources at college, district, region, and system levels by providing just such a trusted clearinghouse where community college faculty, staff, and administrators can find information related to open textbooks. This saves stakeholders the time and effort of culling through an everincreasing list of websites that make questionable claims about providing high-quality free learning content.

In Opening Up Education, Casserly and Smith (2008) contend that in addition to free and open access, the capacity to reuse and remix open content distinguishes it from other content that is now readily available via the Internet. They state:

Fully open educational resources provide a license that grants permission to users not only to read the material but also to download, modify, and post it for reuse. Users are empowered to change the materials to meet their own needs. They can mix and remix. The capacity and right to reuse materials is an important step in providing users all over the world the opportunity to actively participate in the open education resources teaching and learning processes. It creates the opportunity for the localization of the materials, where users tailor materials according to their 
language and culture, and for personalization, where materials can be adapted and modified for individual learners. Reuse also makes possible continuous cycles of improvement of educational materials as users quickly provide critical reactions and evaluations to developers of the quality and effectiveness of the materials. These fast feedback loops of users and developers create an environment for the improvement of content similar to the environment of open source software. (p. 262)

Key to successful and sustained use of open textbooks by educators is a viable tool for college educators to develop, customize, and disseminate learning content for use in the classroom. Connexions at Rice University provides an effective means for educators to contribute and to share open textbooks. Connexions distinguishes itself from other learning content repositories by providing authors with a way to copy, to customize, to share, and to disseminate open textbooks rather than merely providing access.

\section{Connexions}

Founded in 1999 at Rice University, the Connexions repository (see http://cnx.org) provides an effective means for educators to create, modify, share, and disseminate open textbooks under the Creative Commons Attribution license. Connexions repository is a globally accessible and permanent collection of openly available educational content. Use of content posted to Connexions is free for instructors or students to view, to repurpose, or to download as a PDF, including entire textbooks. Connexions provides a complete publishing platform for open textbook projects like CCOTP.

Connexions provides tools to authors for creating content that ranges from single-topic treatments to complete textbooks. Instructors can create integrated textbooks from any of the modular content already in the Connexions repository and from any content created or imported by the instructor. These integrated textbooks are available freely online to students. Connexions can also be used to produce a PDF of the integrated textbook that can be read off-line, sent to a local printer, or sent to Connexions' print-on-demand partner, QOOP. Use of content posted to Connexions in combination with QOOP's print-on-demand technology can produce a printed copy of the textbook at a fraction of the cost of a traditional textbook. The cost of the textbooks becomes independent of the number produced, rendering customized books more feasible. Also, Connexions provides a feature called a lens, which allows educators and organizations to vet and endorse content in the repository, much the way they do in the traditional print world.

Connexions is both a means to create textbooks and a globally accessibly, permanent, and highly searchable repository to house open textbooks, enabling faculty and students to easily locate open textbooks and relevant OER for use in their classes. Note that faculty are also able to customize and affordably print open educational materials on-demand, either via Connexions' print facility (QOOP) or locally. Connexions' material is stored in a semantic XML format that describes what something means rather than how it should be displayed. XML is the engine 
behind the online, offline, and print versions of the book, and it accelerates the process for achieving compliance with the Americans with Disabilities Act for digital content. The licensing structure of Connexions allows information to be ported to other platforms for increased distribution pathways. In combination with QOOP's print-on-demand technology, students can also order an open textbook at a fraction of the cost of a traditional textbook.

\section{Open Textbook Proof-of-Concept}

Throughout 2008, CCCOER collaborated with Connexions to identify a workflow process that would support adoption of open textbooks. The role of Connexions in the CCOTP was to provide a publishing platform for open textbook projects. The CCCOER acted as a liaison between community college faculty, open textbook authors, and Connexions, and it hosted student focus groups to test the open textbook site. Prior to the collaboration between the CCOTP and Connexions in 2008, community college educators had marginal participation in the development of open textbooks. The collaboration between CCCOER and Connexions resulted in a proof-ofconcept open textbook titled Collaborative Statistics (see http://cnx.org/content/col10522/latest/), available for students in introductory statistics courses to view online or to download for free. A teacher's guide is also available, along with a syllabus, practice exams, calculator instructions, and lecture videos. Collaborative Statistics is also available at low cost (\$31.98) in a print (bound) version from QOOP, Inc.

At the time of the CCOTP's launch, a proof-of-concept opportunity presented itself with the purchase of rights to the Collaborative Statistics textbook by the Maxfield Foundation. The textbook was subsequently given open licensing with a Creative Common Attribution license and efforts were underway to make it available via Connexions. Then, Connexions staff converted Collaborative Statistics from a traditional textbook into an open, online textbook. Since the time Collaborative Statistics was posted, other statistics instructors have created versions modified from the original (derived works) with assistance from Connexions staff. The authors, Barbara Illowsky and Susan Dean, were motivated to make their Collaborative Statistics textbook available via an open license in Connexions in order to lower textbook costs for students and to provide more instructional options for teachers (see http://creativecommons.org/weblog/lessigletters/2008/12/03/11112).

Part of the CCOTP one-year feasibility study involved determining a sustainable workflow for the development and use of open textbooks. The CCOTP staff carefully documented the workflow process and shared suggestions for improving the user interface. Recently, the CCOTP posted three additional math open textbooks to Connexions, Elementary Algebra (see http://cnx.org/content/col10614), and two others, which are in PDF format and await conversion to CNXML. During the fall 2008 semester, Collaborative Statistics was adopted by 15 instructors at five different colleges and universities. In the fall of 2008 and winter/spring of 2009 sessions combined, Collaborative Statistics was adopted for use in at least 43 course sections at 10 colleges in the United States and one high school in Ontario, Canada. Since fall 2008, 25 college and university instructors have adopted the Collaborative Statistics textbook. 
CCOTP leaders secured the participation of faculty within the Foothill-De Anza Community College District, SUNY-Purchase, and Mesa College to pilot the Collaborative Statistics textbook during summer and fall of 2008. Two faculty members piloted the textbook during summer of 2008, and 11 faculty members used the textbook in their fall 2008 statistics classes. In winter/spring 2009, the CCOT Project estimates that Collaborative Statistics was adopted for use in at least 25 course sections including courses taught at Arkansas Tech University, De Anza College, Frederick Community College, Mesa College, Sacramento City College, University of Colorado, San Francisco State University, SUNY-Purchase, University of Toledo, and Virginia Tech University.

\section{Collaborative Statistics}

The Collaborative Statistics textbook emphasizes applications of statistical knowledge over the theory behind it. The textbook was written for students enrolled in introductory statistics courses at two- and four-year colleges, who are majoring in fields other than math or engineering. Peer reviews of Collaborative Statistics were conducted in 2009 and are available at http://www.collegeopentextbooks.org/mathreviews.html.

According to Illowsky, posting Collaborative Statistics on Connexions has improved the textbook: "Connexions has much improved our book with what they have done on the cnx.org site. They have broken down the content into modules that can be linked together and arranged in different ways" (Park, 2008).

An open statistics course developed by Illowsky and Dean, freely available from the open courseware Sofia website (see http://sofia.fhda.edu/gallery/statistics/index.html), is closely aligned with the Collaborative Statistics textbook. The open statistics course at Sofia includes lesson plans, videotaped lectures, suggested homework, quizzes, and exams.

The Connexions content team has finished its work on the Collaborative Statistics project. Three collections (246 modules) have been published: 1) Collaborative Statistics (textbook, see http://cnx.org/content/col10522/latest/); 2) Collaborative Statistics Supplemental Course Materials (Sofia content, see http://cnx.org/content/col10586/latest/); and 3) Collaborative Statistics Teacher's Guide ( see http://cnx.org/content/col10547/latest/). CCOTP and Connexions developed a new Connexions module titled Adoption and Usage. This module (see http://cnx.org/content/m18261/latest/) tracks the various versions and derived copies of Collaborative Statistics and lists faculty adopters.

Several instructors have contributed additional content for the Collaborative Statistics textbook (e.g., Minitab instructions and homework problem sets); the latter will be edited for inclusion by the Collaborative Statistics textbook authors, Illowsky and Dean. Three versions of Collaborative Statistics have been derived from the original. One version by Terrie Teegarden, a statistics instructor at San Diego Mesa College, incorporates use of Minitab rather than a calculator. Roberta Bloom, a faculty member at De Anza College, modified Collaborative Statistics to create a customized version, which removed several labs and replaced them with her 
own. In addition, she added new homework problems, practice exercises, and examples, and she revised the wording and introduced terminology for z-score.

A pilot-test of the workflow has been underway specific to the use of Connexions to provide Collaborative Statistics as an open textbook. CCOTP staff worked closely with Connexions staff and the textbook's authors throughout the process. Bloom and Dean provided textbook editing and corrections over the summer. CCOTP staff trained and assisted Teegarden extensively as she created her version of Collaborative Statistics, added Minitab labs, and edited the assignments. Another instructor, Miriam Masullo (SUNY-Purchase) has communicated with Illowsky and the CCOTP that she has plans to augment Collaborative Statistics with ANOVA videos and/or lesson plans.

The CCOTP modeled a workflow process for developing, identifying, reviewing, and disseminating open textbooks suitable for community college instruction using Connexions with one statistics and three mathematics textbooks as proof-of-concept. Over the course of about a year during 2008, Connexions, in collaboration with the Institute for the Study of Knowledge Management in Education, conducted a set of user data collection activities targeted at understanding the usage and adoption of the Collaborative Statistics textbook provided on the Connexions platform as part of the CCOTP project. These user research activities consisted of faculty interviews, student discussion groups, questionnaires, online surveys, and pluralistic walkthroughs of the Connexions reader site.

All the user research activities were approached more from the perspective of a design evaluation activity than an exhaustive data collection activity with statistical research goals. The main goal was to understand how well the current content structure and interface worked for the students and faculty who would be using such content. The research focused on identifying any differences in students' and faculty members' perceptions of using the Collaborative Statistics textbook as a printed version in a traditional classroom versus using it as part of a hybrid course and on students' and faculty members' perceptions of the availability of course materials digitally online and as downloadable and printable files. The student group activities focused on book usability and usage and how it integrates with other learning media but did not focus on traditional learning and research goals. In the group exercise, the interactions between the participants themselves, while important, were not the key research interest; their interaction with the study artifact mattered more.

The recruitment criteria for the user touch points were left vague purposefully so as to get a wide variety of participants from both the regular and hybrid sessions. The main criterion for inclusion in the focus group was students' experience with using the printed or online version of Collaborative Statistics. Selected for faculty interviews were faculty members who had taught with both the original printed version of the textbook and the open textbook available at Connexions.

In early 2009, the CCOTP invited 21 instructors from five different colleges and universities who had adopted the Collaborative Statistics open textbook to complete an online questionnaire about 
their students' satisfaction with the textbook and how the textbook was accessed and used. Over one-third ( 8 of 21 ) of those surveyed responded. The results indicate that students' decisions about whether to use the online version of the textbook or to purchase a printed copy are strongly influenced by directions from their instructors. A majority of the instructors (66.7\%) reported that their students were satisfied with the open textbook. Many of the respondents $(62.5 \%)$ indicated that they adopted the open textbook due to the cost for students being lower than would be the case with a traditional textbook.

The CCOTP worked with Wade Ellis and Denny Burzynski, authors of Elementary Algebra and Fundamentals of Mathematics, to give their textbooks an open license and make them available for digitizing and posting on Connexions. In addition, the CCOTP worked with Applied Finite Mathematics textbook author Rupinder Sekhon to open license his textbook and post it to Connexions. In 2009, Connexions posted these three new open textbooks for mathematics.

\section{Lessons Learned}

Connexions identified lessons learned about open textbook production: 1) the importance of a style guide, 2) the advantage of assembly-line workflow, 3) the importance of naming conventions and standard math authoring tools, and 4) the importance of customizing print formatting based on the purpose of the material (e.g., chapter vs. homework or lab). Connexions also identified lessons learned about open textbook use by students and faculty: 1) the value of availability and customizability, 2) the importance of interactivity, 3) the difference in how faculty and students view modularity, 4) the importance of textbook reading navigational aids, and 5) the need for authoring interface improvements.

\section{Lessons from Producing a Textbook}

The process of converting Collaborative Statistics from a traditional textbook to a collection of modules in the Connexions format presented a number of challenges. In particular, the user interface for both authors and users required some redesign based on feedback obtained during the process. In addition, the content team assembled for this project was relatively new to Connexions, requiring rapid on-the-job training and familiarization with Connexions' features and the CNXML and MathML languages while simultaneously producing large numbers of new modules. Along the way, several important lessons were learned regarding best practices for large content projects involving multiple team members.

\section{Importance of a style guide.}

A style guide, or set of standards, is critical in order to effectively distribute content entry efforts among several team members, who must format the content consistently. Because the translation from presentation-oriented source materials to semantically oriented markup requires a combination of language familiarization and subjective interpretation, it is not uncommon for two 
individuals to mark up the same content using two different methods. This can lead to stylistically disjointed modules.

A somewhat informal style guide was created for the Collaborative Statistics project with mixed success. While setting standards for module structures, mathematical representation, etc. helped to keep stylistic differences to a minimum, there were a number of circumstances in which team members were either unaware of a particular style decision or misunderstood the rules for applying those styles. This problem became more pronounced in the later phases of the project as new team members were brought on board without the benefits of project training and clarifications of stylistic standards. In addition, some standards evolved over time as project members became more familiar with the languages and the subtleties involved in content markup, resulting in a stylistic shift over the course of the book.

While having a style guide in place was critical to the success of the project and proved to be an invaluable asset for coordinating individual efforts, a more rigorous and well-defined style guide would have helped to reduce the amount of work involved in reviewing and realigning older modules as well as those marked up by different team members. Perhaps most importantly, this guide must be maintained consistently throughout the lifespan of the projects, both to inform future team members of important stylistic choices (and the logic behind those decisions) and to protect against stylistic shifts over time. While style guides must remain somewhat flexible in order to accommodate the evolving needs of each project, any changes must be carefully considered and existing content retrofitted to reflect any adjustments made along the way.

\section{Advantage of assembly-line workflow.}

The conversion of content from traditional formats to CNXML modules is a complex process involving several discrete steps. In the early stages of the project, each team member was given a set of modules to be completed and each of these steps had to be completed prior to moving on to the next. As team members became more familiar with the process, it became obvious that certain steps were acting as bottlenecks in the workflow. Additionally, each member developed a particular set of strengths and weaknesses. For example, some team members had difficulty proofreading content for errors but could quickly and accurately translate mathematical expressions into MathML.

After a few chapters of dividing work by modules, the project team regrouped and adopted an assembly-line process for module creation. Simple, repetitive steps (e.g., module creation and metadata entry) could be completed more efficiently by assigning a single team member to complete the task for all modules at once, freeing up others to focus on more complex tasks, such as content entry. Those with more experience were assigned to more detail-oriented tasks, such as proofreading and editing the module to meet accessibility standards. Assignments were staggered in such a way as to ensure that each team member was not waiting on another to complete an assignment, allowing each member to complete his or her tasks and immediately move on to the next. In addition to reducing bottlenecks, this approach also limited the exposure of each team member to a specific set of tasks, improving the stylistic uniformity of the project 
and reducing the learning curve for new team members to manageable levels. This assembly-line process greatly improved the speed and accuracy of the translation process, allowing a much more efficient workflow.

\section{Importance of naming conventions and standard authoring tools.}

Over the course of the project, different content team members used different MathML editors, each of which used its own format for presenting mathematical expressions. This inconsistency led to a number of issues, particularly when edits and corrections to existing content were required. Adopting a standard math editor for the project would have helped this situation, allowing each team member to understand what the others had done and how to work with the resulting code.

The use of module naming conventions was identified as crucial. It is difficult to strike a balance between being concise and descriptive, particularly when considering the ability to find the module within the repository. For this project, a standard naming convention was adopted, with the chapter name (e.g., Probability Topics) added before the module subtitle (e.g., Homework), which resulted in a module name (e.g., Probability Topics: Homework) that was descriptive, easy to locate, sortable by chapter in the workgroup, and sufficiently modular to be used in other contexts by other Connexions authors. To put this in perspective, consider for a moment that without such a standard there could easily have been 13 distinct modules titled Homework in the same workgroup, with no way to distinguish between them and no way to inform other authors who might otherwise use them what skills were being assessed. Connexions provides a convenient way to rename modules when they appear in a textbook, so it is straightforward to make sure the textbook's table of contents have simple names without the chapter title attached.

Having a clear, well-defined, and enforced set of standards is essential to the success of such a large project, particularly when several individuals are working towards a common goal. Modules are the fundamental building block in Connexions and they print uniformly within a collection to make the entire collection look consistent. When particular modules play a specific role within a book, however, special styling rules apply. Homework and labs, for instance, need to have problem numbering start over and need to have a page break before and after them. Prefaces and appendices need to be numbered in a particular way within the book, unlike modules being used within traditional chapters. Choices were added to modules and will be added to the collection structure so that all Connexions authors benefit from the enhancements made to the Collaborative Statistics book.

\section{Lessons from Faculty and Students Using the Textbooks}

Based on feedback obtained during the focus groups, students and faculty perceptions of online textbooks differed somewhat. Students value the ability for faculty to customize. Specifically, students find it disconcerting when instructors assign readings in an order that differs from their textbooks. Instructors and students both liked being able to access the material anywhere, and instructors mentioned the ability to link directly to a specific part of the book within their learning 
management system. Students valued the pop-up, in-place glossary definitions and the show and hide exercises, but they wanted more interactivity. Students believed that the books would be even more useful if there were more problems, interactive simulations, and practice quizzes.

Instructors and students viewed modularity very differently. The instructors believed that the book was a bit too modularized and broke up the flow of their lessons. The students claimed the modularity as a benefit; they liked the fact that each concept was broken out and separated and commented that it was easier to consume the information in small chunks. The glossary was readily available from the web page they were reading, and they believed this feature enhanced their understanding of the concepts.

During the focus group interviews, students were observed as always keeping the table of contents open and needing navigation aids to keep track of their reading. The Connexions reader interface was modified to contain a clickable table of contents, checkmarks to show modules that had been read, and a feature that enabled saving content in "My Favorites," a new type of lens. The online display of chapters was made consistent with print since faculty and students must be able to find the same content online and in print.

The Connexions author interface is being redesigned to better fit the needs of authors who are creating textbooks, not just creating collections from Connexions modules. Connexions staff are also redesigning the interface to support large-scale edits and customizations to existing textbooks.

\section{Conclusion}

The CCOTP has identified the following challenges to the production and adoption of open textbooks: 1) faculty members' and students' expectations of high production quality and ancillaries for open textbooks, 2) methods for documenting and maintaining control over various versions, and 3 ) the process of converting existing open content to digital and accessible formats. Connexions holds promise as a means to overcome these challenges.

CCOTP recommends 1) using Connexions as the common repository for open textbook content in an effort to provide greater national and even international access; 2) using Connexions as the tool for sharing, reusing, customizing, and disseminating open textbook content; 3) considering corporate funding, in return for branding, to sponsor the development of content for specific disciplines; 4) approaching publishers to donate content that is going out of print; and 5) identifying the process for storyboarding the development of open textbooks. As a consequence of the collaboration with Connexions, the CCOTP plans to increase the number of open textbooks posted to Connexions, convert open textbooks to CNXML format for posting to the Connexions site, and adapt the print and web display tools to meet identified needs of community college faculty and students. Additionally, technical support must be provided to community college faculty and students. 
Open educational resources must be leveraged to increase the quality, access, and affordability of higher education by identifying, producing, and using open textbooks in community colleges. Most community college faculty members are unfamiliar with the effective use of open and digital textbooks in their classes; they must be encouraged to learn about these new resources in order to enhance the quality and delivery of course materials, increase access for learners, and reduce the essential cost of curriculum materials. With the current global economic crisis, the need to minimize financial barriers to education has become increasingly salient. Open textbooks and community colleges both serve to increase access to education for students with limited means.

The CCOTP, through the Connexions platform, affords faculty the opportunity to reclaim greater control over their curriculum by making it convenient to explore feasible alternatives to high-cost publishers' textbooks. Additionally, with the use of open textbooks in Connexions, faculty are able to customize the content to best suit the regional or local needs of their students rather than having to adjust their own instruction to match publishers' textbooks. Students who take courses with open textbooks can benefit from the lower cost of learning materials, thereby giving them greater flexibility with their education budgets. 


\section{References}

Annand, D. (2008). Learning efficacy and cost-effectiveness of print versus e-book instructional material in an introductory financial accounting course. Journal of Interactive Online Learning, 7(2), 152-164.

Baker, D. (2005). Are copyrights a textbook scam? Alternatives to financing textbook production in the 21st century. Retrieved from Center for Economic and Policy Research website: http://www.cepr.net/documents/publications/textbook_2005_09.pdf.

Baker, J. (2008). Culture of shared knowledge: Developing a strategy for low-cost textbook alternatives. New England Journal of Higher Education, 21(1), 30.

Buczynski, J. A. (2007). Faculty begin to replace textbooks with "freely" accessible online resources. Internet Reference Services Quarterly, 11(4), 169-179.

Casserly, C.M., \& Smith, M.S. (2008). Revolutionizing education through innovation: Can openness transform teaching and learning? In T. Iiyoshi \& M.S.V. Kumar (Eds.), Opening up education: The collective advancement of education through open technology, open content, and open knowledge (pp. 262-3). Cambridge, MA: MIT Press.

Davy, T. (2007). E-textbooks: Opportunities, innovations, distractions and dilemmas. Serials: The Journal for the Serials Community, 20(2), 98-102.

Hobbs, R., Jaszi, P., \& Aufderheide, P. (2007, September). Cost of copyright restrictions for media literacy. Retrieved from Center for Social Media at American University School of Communication website: http://aladinrc.wrlc.org/dspace/bitstream/1961/4607/1/Final_CSM_copyright_report.pdf.

Park, J. (December, 2008). Collaborative statistics-An open textbook model. Retrieved from http://creativecommons.org/weblog/lessig-letters/2008/12/03/11112.

Young, J. (2008). Textbook piracy grows online, prompting a counterattack from publishers.

The Chronicle of Higher Education. Retrieved from http://chronicle.com/article/Textbook-Piracy-Grows-Onlin/949/. 